\title{
A Novel Design of Frequency Reconfigurable Antenna for 5G Mobile Terminal Equipment
}

\author{
Yu Qi, Yi-hu Xu* \\ Dept. of Electronic Communication Engineering, Yanbian University, Yanji, 133002, China. \\ * Corresponding author. Tel.: 15567602443; email: xuyh@ybu.edu.cn \\ Manuscript submitted January 27, 2020; accepted March 8, 2020. \\ doi: 10.17706/ijcce.2020.9.3.134-140
}

\begin{abstract}
The development of 5G New Radio (NR) is widely concerned. In order to solve the problem of working frequency band, a design scheme of frequency reconfigurable antenna module covering $3.5 \mathrm{GHz}$ and $4.9 \mathrm{GHz}$ frequency band is proposed in this paper. It can be applied to $3.4-3.6 \mathrm{GHz}$ band and $4.8-5.0 \mathrm{GHz}$ band, which can meet the application of sub $6 \mathrm{GHz}$ band in $5 \mathrm{G}$ communication. The antenna module adopts a feed port, a tune stub, and five switches which can realize frequency reconfiguration. In this paper, the analysis of the parameters of the ground plane and the length of the tune stub is given, and the discussions of the S-parameter, the simulated electrical field distributions, the radiation pattern, the voltage standing wave ratio (VSWR) and the Smith chart are also given, which proves the practicability of the proposed antenna. The size of the antenna module is suitable and the performance is excellent.
\end{abstract}

Key words: $5 \mathrm{G}$ new radio, frequency reconfigurable, multi-band, microstrip antenna.

\section{Introduction}

Nowadays, 5G network has gradually become commercial. The frequency planning defines $3.4 \mathrm{GHz}-3.6$ $\mathrm{GHz}$ and $4.8 \mathrm{GHz}-5.0 \mathrm{GHz}$ as the working frequency band of the $5 \mathrm{G}$ communication system. As the mobile terminal equipment gradually turns to high screen share and high intelligence, the terminal antenna presents the development trend of miniaturization, multi frequency, broadband and low mutual coupling [1] , [2]. As a result, the design of the terminal antenna becomes more and more difficult and innovative. The scheme that can not only increase the application flexibility of the antenna, but also save the occupied space is to make an antenna module work in multiple resonant frequency bands. Some antenna modules are designed either only for LTE / WWAN applications in 4G band [3], or only for 5G communication in a single band, such as in [4], [5], or multi band modules exist independently [6], [7]. In view of the above problems, if the frequency reconfigurable technology is used that only one antenna module is used to meet all the sub 6G working band applications, the working flexibility and space utilization of terminal equipment can be greatly improved. For the design of frequency reconfigurable antenna, such as the antenna in [8] is designed for $4 \mathrm{G}$ band. And the size of frequency reconfigurable antenna array proposed in [9] is large, which is not suitable for the mobile terminals.

In this paper, a frequency reconfigurable antenna module for $5 \mathrm{G}$ communication is proposed. The proposed antenna module is a curved monopole belt structure containing a switch pack, which can switch the application frequency band. Moreover, the 10-dB impedance bandwidths (2:1 VSWR) of $11.8 \%$ (3296 $\mathrm{MHz}-3710 \mathrm{MHz}$ ) and $14.8 \%$ (4578 MHz - $5310 \mathrm{MHz}$ ) respectively, covering $3.5 \mathrm{GHz}$ and $4.9 \mathrm{GHz}$ frequency 
bands. Ground parameters and stub parameters are analyzed. S parameter, VSWR and radiation pattern are also given in the thesis. Results show that the proposed antenna module can meet the requirements of various frequency bands.

\section{Parameter Design of Frequency Reconfigurable Antenna}

The proposed frequency reconfigurable antenna module has five switches, divisible into two groups, those are used to control the access length of the entire radiator. A complete model detailing the antenna is shown in Fig. 1 (a). As shown in Fig. 1 (a), the antenna includes a tune stub that can fine tune the resonant frequency of the antenna and a feed port which provides excitation. Fig. 1 (b) and Fig. 1 (c) are the schematic diagram of antenna module working in $3.5 \mathrm{GHz}$ and $4.9 \mathrm{GHz}$ frequency bands respectively. The state configurations from the conditions of the switches are shown in Table 1. In the first state which declares 3.5 GHz band, switch (1) and (2) are disconnected and switch (3) - (5) are closed, the total length of radiator is $35 \mathrm{~mm}$. In the second state which declares $4.9 \mathrm{GHz}$ band, switch (1) and (2) are closed and switch (3) - (5) are disconnected, the total length of radiator is $25.6 \mathrm{~mm}$.

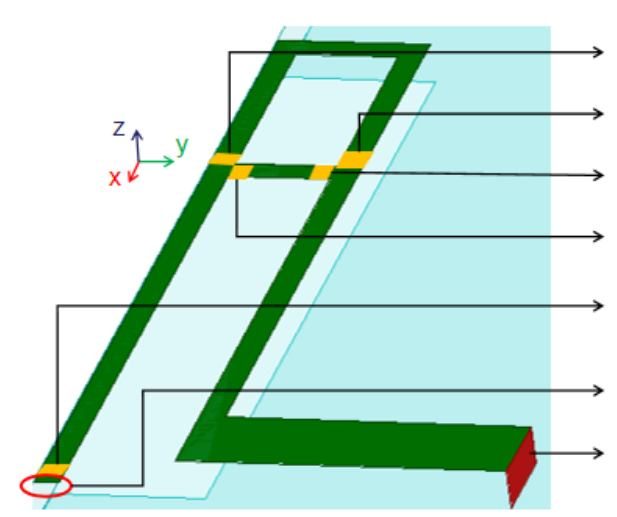

(a)

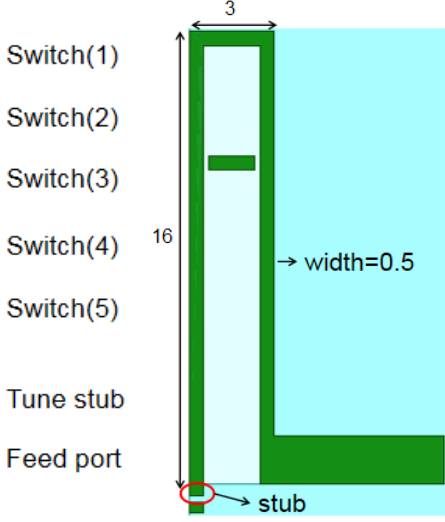

(b)

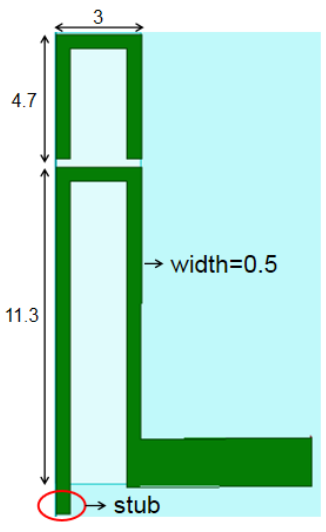

(c)

Fig. 1. Model of frequency reconfigurable antenna module: (a) frequency reconfigurable antenna, (b) 3.5 $\mathrm{GHz}$ band, and (c) $4.9 \mathrm{GHz}$ band.

Table 1. State Configurations from the Switches' on/off Conditions

\begin{tabular}{cccccc}
\hline \hline State & Switch(1) & Switch(2) & Switch(3) & Switch(4) & Switch(5) \\
\hline $3.5 \mathrm{GHz}$ & On & On & Off & Off & Off \\
$4.9 \mathrm{GHz}$ & Off & Off & On & On & On \\
\hline \hline
\end{tabular}

\subsection{Analysis of Variable Ground}

In this part, the variable analysis of antenna module metal ground is carried out. The analysis of the variable ground includes the parameters ground-length and ground-width. The change of variable ground-width has little effect on the working center frequency, but has some effect on return loss parameter. When ground-width $=25 \mathrm{~mm}$ or $30 \mathrm{~mm}, \mathrm{~S} 11$ parameter are better, which can reach $-27.3 \mathrm{~dB}$ and $-25.78 \mathrm{~dB}$ in two frequency bands, respectively. The change of the variable ground-length will cause a certain degree of offset to the resonant frequency of the antenna module. And for two frequency bands, when ground-length is $30 \mathrm{~mm}$ or $35 \mathrm{~mm}, \mathrm{~S} 11$ is the best, which can reach $-25.56 \mathrm{~dB}$ and $-32.68 \mathrm{~dB}$ respectively.

According to the above data, Fig. 2 shows the results of the analysis when ground $=30 \mathrm{~mm} \times 30 \mathrm{~mm}$ and ground $=35 \mathrm{~mm} \times 35 \mathrm{~mm}$. The two ground conditions have negligible effect on the proposed frequency reconfigurable antenna operating in $3.5 \mathrm{GHz}$ frequency band. When antenna is applied to $4.9 \mathrm{GHz}$ band, S11 
parameter is optimized from $-24.29 \mathrm{~dB}$ to $-38.25 \mathrm{~dB}$ at the center frequency due to the change of the ground. Therefore, when variable ground changes from $35 \mathrm{~mm} \times 35 \mathrm{~mm}$ to $30 \mathrm{~mm} \times 30 \mathrm{~mm}$, not only the size of the antenna can be reasonably reduced, but also the S11 parameters in the $4.9 \mathrm{GHz}$ frequency band can be adjusted, so that the antenna performance can become better. In the following design, this paper selects the variable case of metal ground of $30 \mathrm{~mm} \times 30 \mathrm{~mm}$.

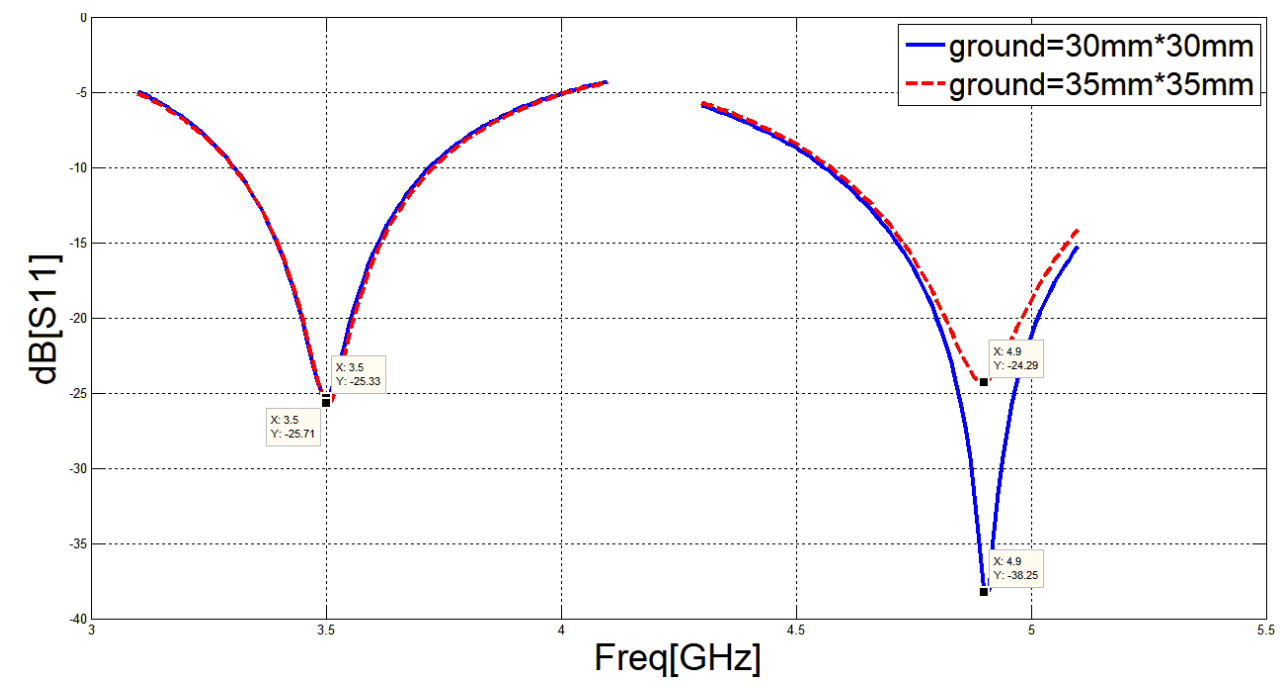

Fig. 2. Simulated S11 Parameters in two ground cases.

\subsection{Analysis of Variable Stub}

The tune stub can fine tune the resonant frequency of the antenna by adjusting the length. For different ground cases and different application frequency bands, the length of stub will be different. Therefore, in this part, numerical analysis is carried out for the variable stub when the proposed antenna works in two frequency bands. The analysis results are shown in Fig. 3. Fig. 3 (a) and Fig. 3 (b) respectively show the analysis of variable stub when the antenna works in the $3.5 \mathrm{GHz}$ and $4.9 \mathrm{GHz}$ frequency bands.

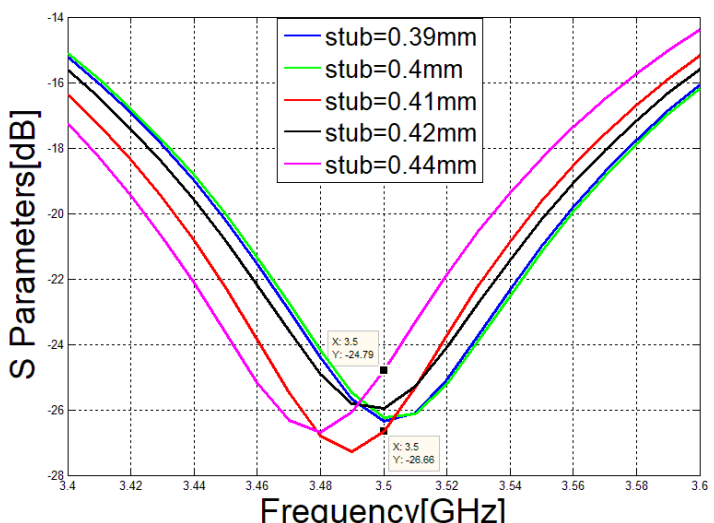

(a)

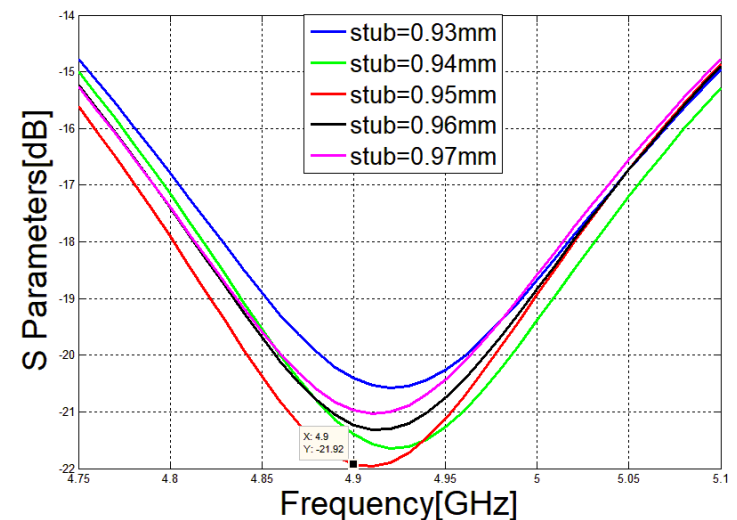

(b)

Fig. 3. Analysis of variables stub in (a) $3.5 \mathrm{GHz}$ and (b) $4.9 \mathrm{GHz}$ band.

For $3.5 \mathrm{GHz}$ band, when stub $=0.41 \mathrm{~mm}$, the center frequency of the proposed antenna module is slightly offset, but the overall S11 is better, changing from $-26.33 \mathrm{~dB}$ (stub $=0.39 \mathrm{~mm}$ ) to $-27.28 \mathrm{~dB}$. Therefore, stub $=0.41 \mathrm{~mm}$ can be selected in this frequency band. And for $4.9 \mathrm{GHz}$ band, it is obvious that when stub $=0.95$ $\mathrm{mm}, \mathrm{S} 11$ parameter is $-21.96 \mathrm{~dB}$, which is slightly better than other cases. 


\section{Results \& discussion}

According to the above variable analysis, when the variable takes the above fixed value, that is, the variable ground $=30 \mathrm{~mm} \times 30 \mathrm{~mm}$, and the variable stub is $0.41 \mathrm{~mm}$ and $0.95 \mathrm{~mm}$ in two frequency bands respectively. Simulated analysis of the proposed antenna module is given in this section.

Fig. 4 shows the simulated S parameters of the proposed antenna. VSWR and Smith chart of the proposed frequency reconfigurable antenna module are given in Fig. 5 and Fig. 6.

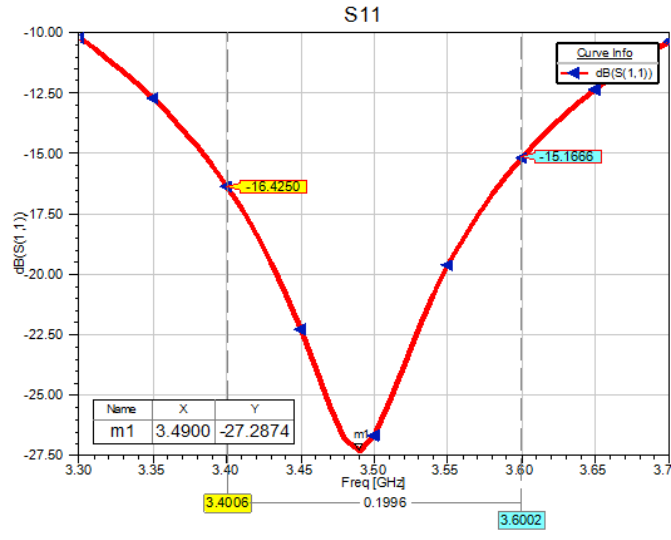

(a)

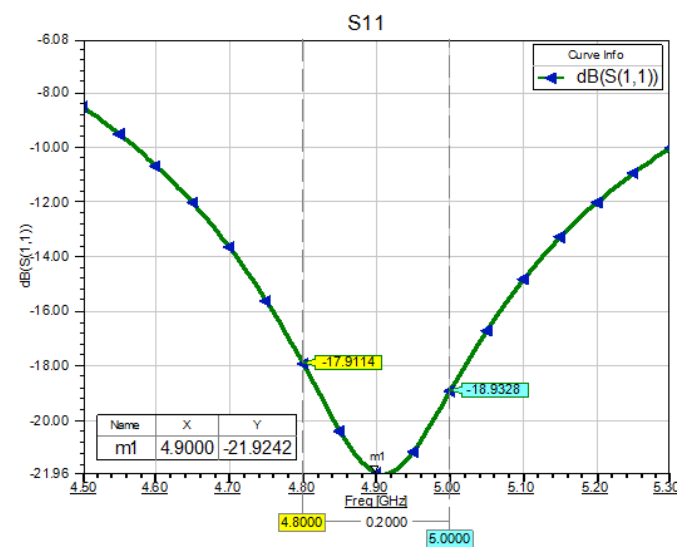

(b)

Fig. 4. Simulated S parameters of frequency reconfigurable antenna: (a) $3.5 \mathrm{GHz}$ band, (b) $4.9 \mathrm{GHz}$ band.

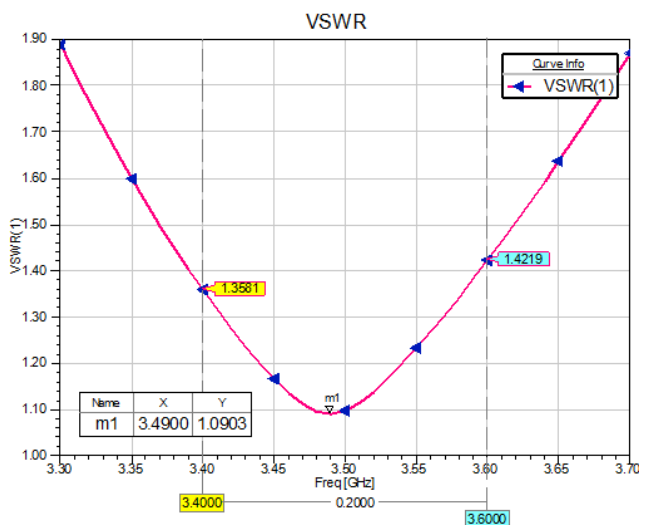

(a)

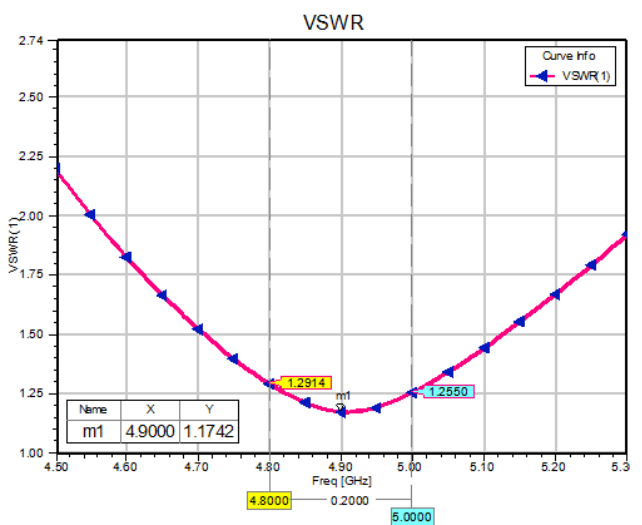

(b)

Fig. 5. VSWR of frequency reconfigurable antenna module in (a) $3.5 \mathrm{GHz}$ and (b) $4.9 \mathrm{GHz}$ frequency bands.

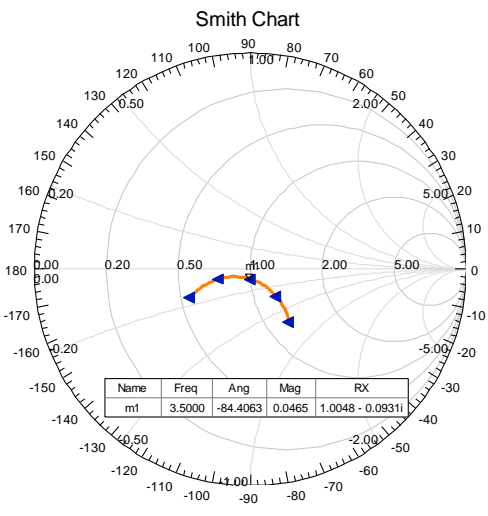

(a)

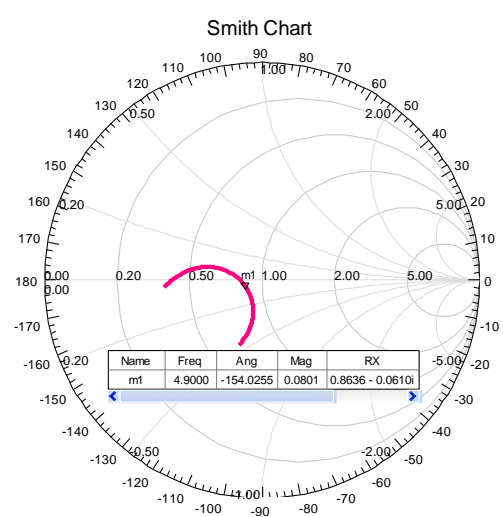

(b)

Fig. 6. Smith Chart of frequency reconfigurable antenna: in (a) $3.5 \mathrm{GHz}$ and (b) $4.9 \mathrm{GHz}$ frequency bands. 
As shown in the figures, when the frequency reconfigurable antenna module is applied in the $3.4 \mathrm{GHz}$ 3.6 $\mathrm{GHz}$ frequency band, $\mathrm{S} 11$ parameters are below $-15.15 \mathrm{~dB}$, and can reach $-27.28 \mathrm{~dB}$ at the center frequency. Moreover, the VSWR is lower than 1.42, and it is as low as 1.09 at the center frequency, which is close to 1. It means that antenna matches well. When the antenna covers $4.8 \mathrm{GHz}-5.0 \mathrm{GHz}$, the return loss parameters are better than $-17.91 \mathrm{~dB}$, and the optimal value is $-21.92 \mathrm{~dB}$. The VSWR is lower than 1.29 , which is up to 1.17 at the center frequency, with little change and good antenna matching.

Fig. 7 shows the return loss of the proposed antenna and an antenna (Ref) which is designed for $3.5 \mathrm{GHz}$ frequency band in a reference. In the $3400 \mathrm{MHz}-3600 \mathrm{MHz}$ frequency band, the simulated S11 parameters of the antenna module at the center frequency change from $-22.7 \mathrm{~dB}$ to $-26.4 \mathrm{~dB}$. It can be concluded that the bandwidth and return loss of the proposed antenna module are both better.

The simulated surface current distributions of the proposed antenna in $3.5 \mathrm{GHz}$ and $4.9 \mathrm{GHz}$ frequency bands are provided in Fig. 8. It shows that the mode of the antenna module is a higher-order resonance.

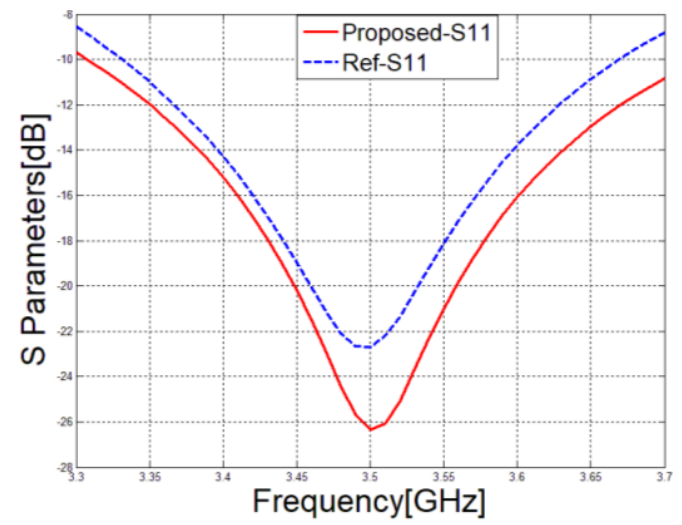

Fig. 7. Simulated S parameters of proposed antenna and Ref.

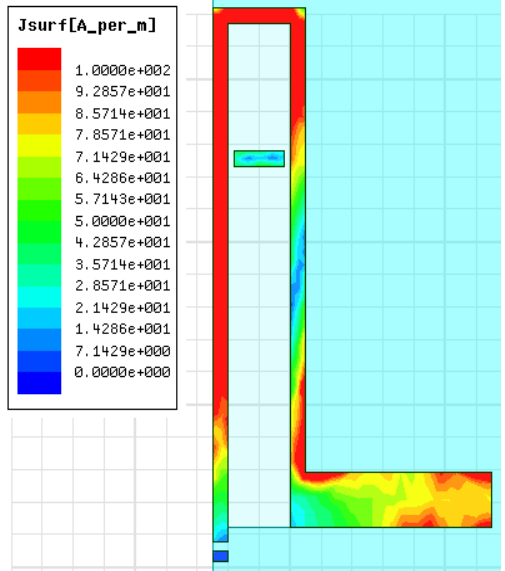

(a)

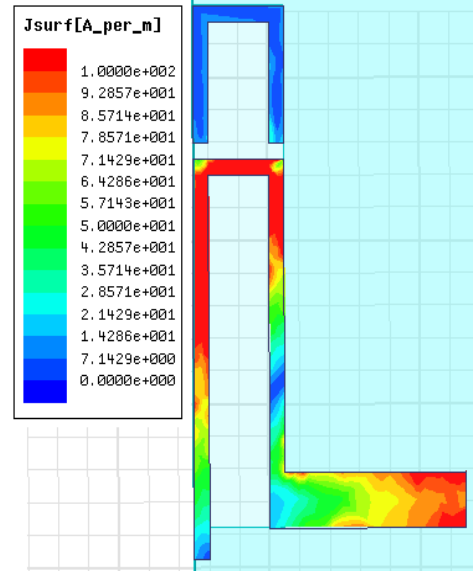

(b)

Fig. 8. Simulated surface current distributions of antenna in (a) $3.5 \mathrm{GHz}$ and (b) $4.9 \mathrm{GHz}$ frequency bands.

And Fig. 9 shows the simulated radiation pattern in XZ plane, YZ plane and XY plane in two frequency bands. The radiation pattern of the antenna in the two frequency bands is basically similar. There is slight deformation, considering that the return loss is different when the antenna switches to $3.5 \mathrm{GHz}$ and $4.9 \mathrm{GHz}$ frequency bands. That is to say, compared with the $3.5 \mathrm{GHz}$ band, the antenna has a poor matching condition in the $4.9 \mathrm{GHz}$ band. However, the radiation pattern is basically the same, and both $\mathrm{XY}$ and YZ planes have demonstrated broadside patterns in the $-\mathrm{Y}\left(-90^{\circ}\right)$ direction. 


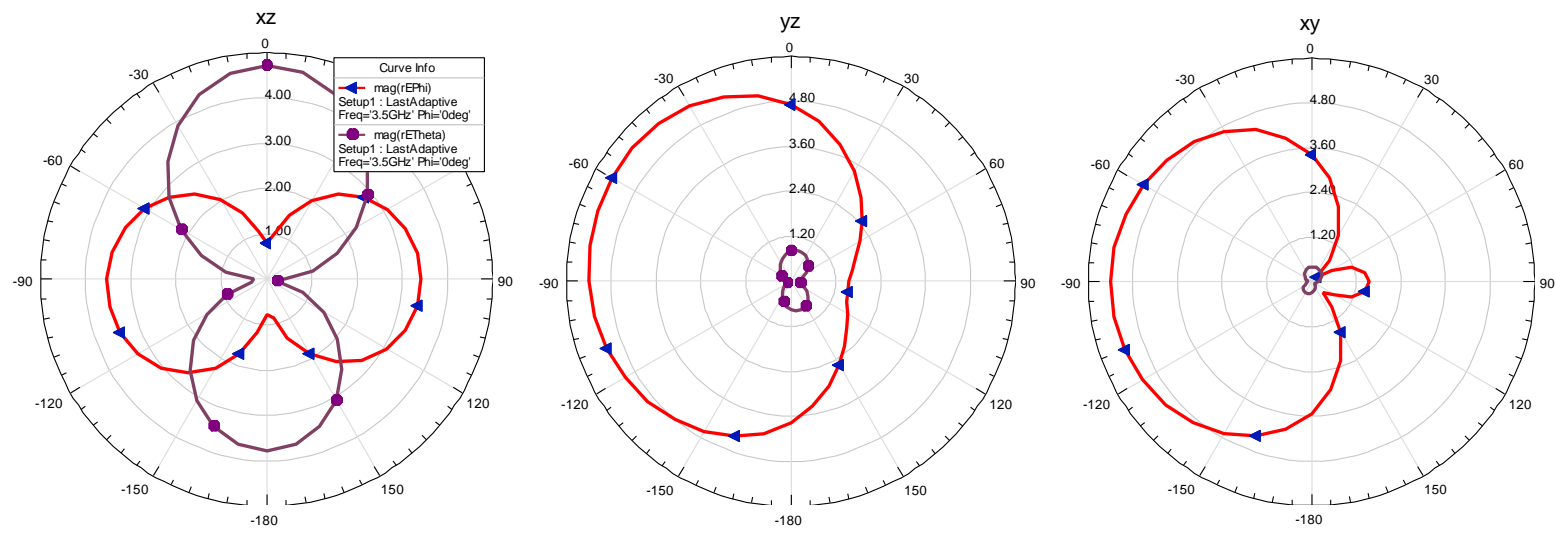

(a)
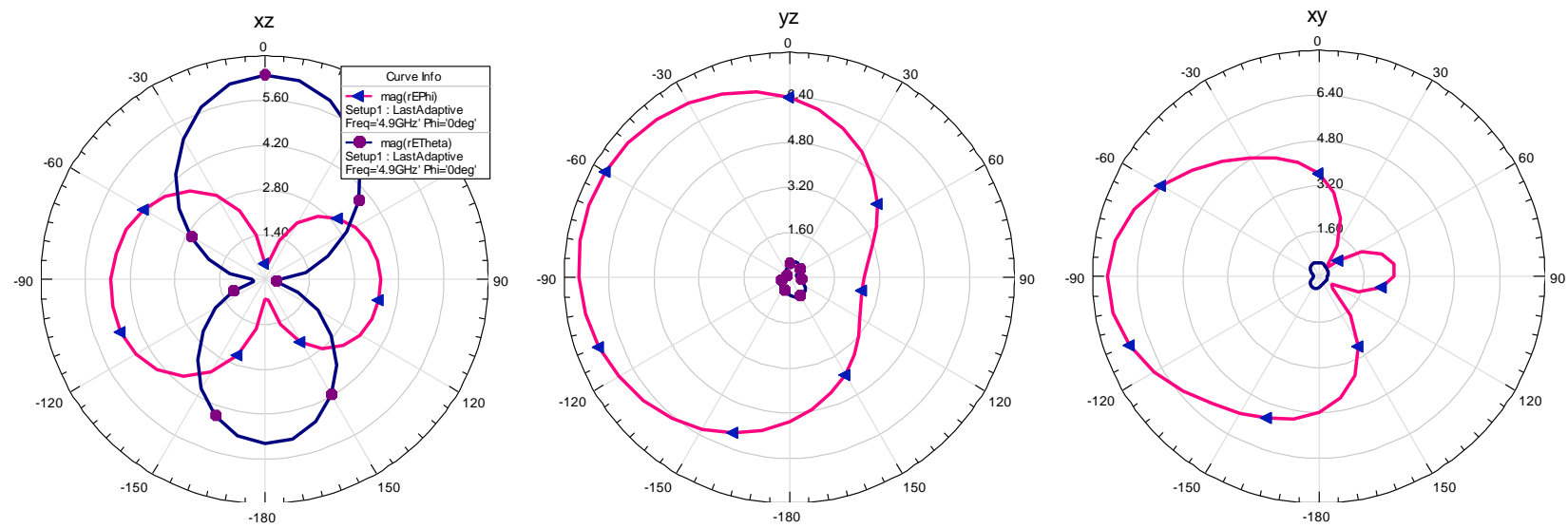

(b)

Fig. 9. Simulated radiation pattern in (a) $3.5 \mathrm{GHz}$ and (b) $4.9 \mathrm{GHz}$ frequency bands.

\section{Conclusion}

With the continuous development and commercial use of the fifth generation mobile communication technology, people's requirements for mobile terminals are increasing. In this paper, a design of antenna module based on frequency reconfigurable technology which can be applied to mobile terminal equipment is proposed. It can be switched on two working frequency by loading the switch group. And the 10-dB impedance bandwidths of $11.8 \%$ and $14.8 \%$ respectively, covering $3.5 \mathrm{GHz}(3400 \mathrm{MHz}-3600 \mathrm{MHz}$ ) and 4.9 $\mathrm{GHz}(4800 \mathrm{MHz}-5000 \mathrm{MHz}$ ) frequency bands, which meets the mobile terminal for 5G spectrum application. In addition, the simulation results show that when the frequency reconfigurable antenna switches the resonant frequency, S11 is always better than $-15 \mathrm{~dB}$, and the antenna matches well.

\section{Conflict of Interest}

The authors declare no conflict of interest.

\section{Author Contributions}

The first author, Yu Qi, carried out many parts of the article, including abstract, introduction, design \& analysis, results \& discussion, conclusion. The second author, Yi-hu Xu, analyzed and interpreted the data, and proofread the whole paper format; all authors had approved the final version.

\section{References}

[1] 3GPP Technical Specification Group Radio Access Network. (2019, December). SNR Requirements on 
User Equipments (UEs) supporting a release-independent frequency band. Release 16; 3GPP TS 38.307, V 16.1.0.

[2] Bleicher, A. (2013, July). The 5G phone future. IEEE Spectr., 50(7), 15-16.

[3] Ban, Y.-L., Chen, Z.-X., Chen, Z., Kang, K., \& Li, J. L.-W. (2014). Decoupled closely spaced heptaband antenna array for WWAN/LTE smartphone applications. IEEE Antennas Wireless Propag. Lett, 13, 3134.

[4] Xu, K.-D., Liao, S.-W., \& Xue, Q. (2018). Wideband patch antenna using multiple parasitic patches and its array application with mutual coupling reduction. IEEE Access, 6, 42497-42505.

[5] Ding, C. F., Zhang, X. Y., Xue, C.-D., \& Sim, C.-D. (2018, October). Novel pattern-diversity-based decoupling method and its application to multielement MIMO antenna. IEEE Trans. Antennas Propag., 66(10), 4976-4985.

[6] Pan, B.-C., \& Cui, T.-J. (2017, October). Broadband decoupling network for dual-band microstrip patch antennas. IEEE Trans. Antennas Propag., 65(10), 5595-5598.

[7] Ban, Y.-L., Li, C., Sim, C. Y. D., et al. (2016). 4G/5G multiple antennas for future multi-mode smartphone applications. IEEE Access, 4, 2981-2988.

[8] Lian, R.-N., Tang, Z.-Y., \& Yin, Y.-Z. (2018, January). Design of a broadband polarization-reconfigurable fabry-perot resonator antenna. IEEE Antennas and Wireless Propag., 17(1), 122-125.

[9] Nie, Z., Zhai, H., Liu, L., Li, J., Hu, D., \& Shi, J. (2019, June). A dual-polarized frequency-reconfigurable low-profile antenna with harmonic suppression for 5G application. IEEE Antennas and Wireless Propag., Lett., 18(6), 1228-1232.

Copyright (C) 2020 by the authors. This is an open access article distributed under the Creative Commons Attribution License which permits unrestricted use, distribution, and reproduction in any medium,

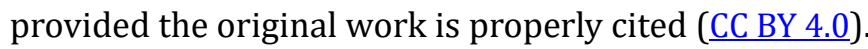

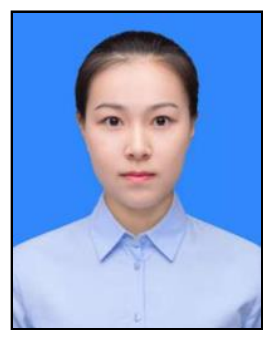

Yu Qi was born in Jilin province of China. She completed bachelor degree in the field of electronics and telecommunication, Yanbian University, Yanji, China, in 2018.

She is still pursuing her master degree in Yanbian University, Yanji, China. Her research interests include the massive MIMO and large scale antenna arrays.

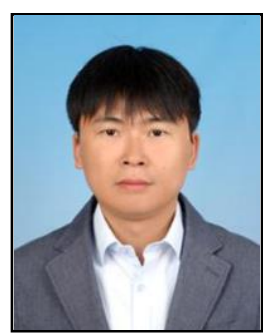

Yi-hu Xu was born in Jilin province of China. He received the Ph.D. degree in electronics engineering from the Chonbuk National University, Korea, in 2014.

$\mathrm{He}$ is an associate professor of the Division of Electronics and Communication Engineering, Yanbian University, Yanji, China. His research interests include cognitive radio and $5 \mathrm{G}$ NR communications. 